\title{
RELIABILITY ASSESSMENT AND SCREENING BY RELIABILITY INDICATOR METHODS
}

\author{
J $\phi$ RGEN M $\phi$ LTOFT \\ The Engineering Academy of Denmark, Building 451, DK-2800 Lyngby, Denmark
}

(Received October 20, 1982; in final form January 28, 1983)

Built-in flaws in electronic components have been recognized as a serious cause of failure. They are difficult to screen away by conventional methods because the times-to-failures for component working in systems are often rather long and because accelerated burn-in may screen by the wrong failure mechanisms. As an alternative, the concept and possible use of reliability indicator methods are discussed and some recently developed methods described.

\section{THE NECESSITY FOR RELIABILITY INDICATOR METHODS}

Recent research as well as experience from lifetests and field performances have revealed that electronic components during their useful lives do not fail from random overloads, but rather from flaws developing into failures after a certain time. The flaws may be attributed either to the component manufacturing process being out of control (built-in flaws) or to damage added during the equipment assembling process (induced flaws).

However, more important is that in general the built-in flaws develop into failures con. siderably later than the induced flaws. While the induced flaws give failures within some hundred hours, the built-in flaws give failures in the region from 500 to 2000 hours or more. Figure 1 illustrates this concept in terms of the failure rate function $h(t)$ and the corresponding cumulative failure distribution function $\mathrm{F}(\mathrm{t})$. Reference ${ }^{1,2}$ give a comprehensive treatment of the mathematical background and show some of the experimental evidence.

As seen from Figure 1 the failure rate function has no longer the traditional often quoted "bathtub"-curve shape and the c.d.f. follows a characteristic S-shaped curve as a result of the bi/trimodal nature of the failure distribution. It should be noticed that the wear-out part of the pattern is rather speculative, as several authors of papers in the last couple of years have contended an ever decreasing failure rate, rather than the increasing failure rate suggested by Figure 1.

From this picture it is obvious that the most serious problem is the built-in flaws. The induced flaws can be rectified either by improving the assembly process or by system burn-in. In theory the built-in flaws could be treated in the same way e.g. either by improvements in the component manufacturing process or by component burn-in.

However, the relatively long times-to-failures make these solutions impractical in many cases, because it will be necessary to make use of accelerated testing and it is very easy to accelerate failure mechanisms different from the mechanisms actually occurring in the field.

There is apparently a need for another approach and this may be the use of reliability indicator methods e.g. screening out components which are suspected of having built-in flaws. 
Failure rate [failures $/ 10^{6} \mathrm{~h}$ ]

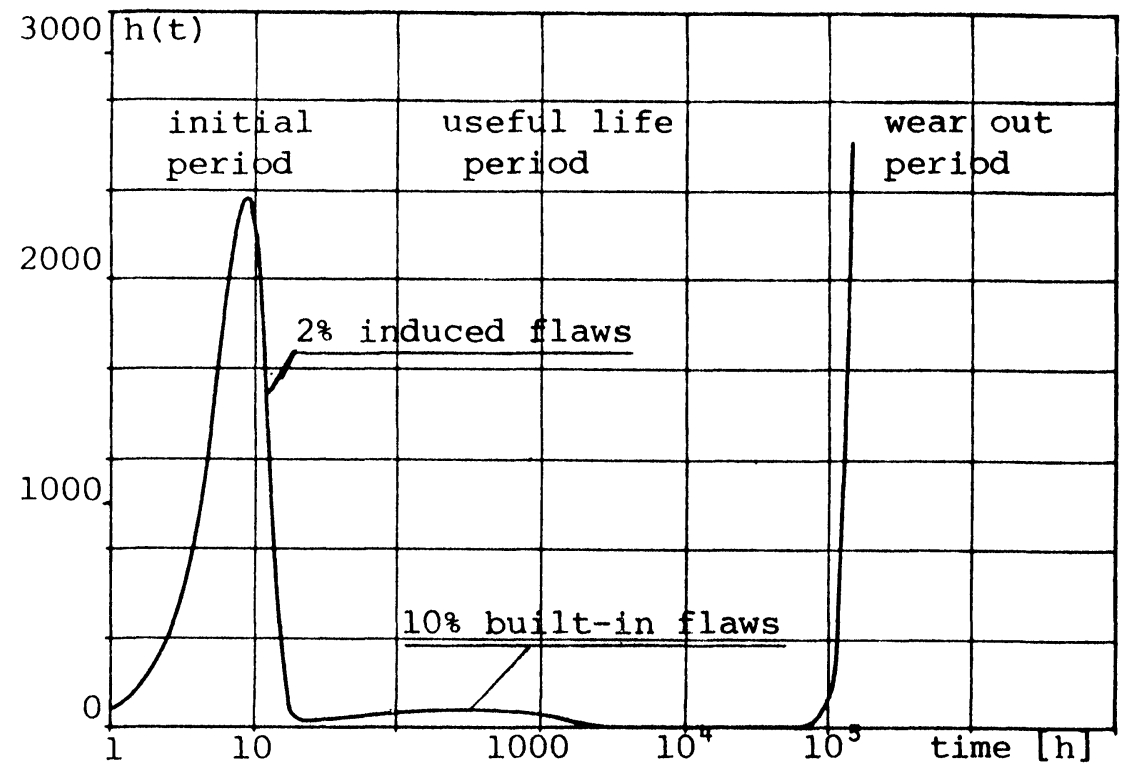

c.d.f.Weibull probability[8]

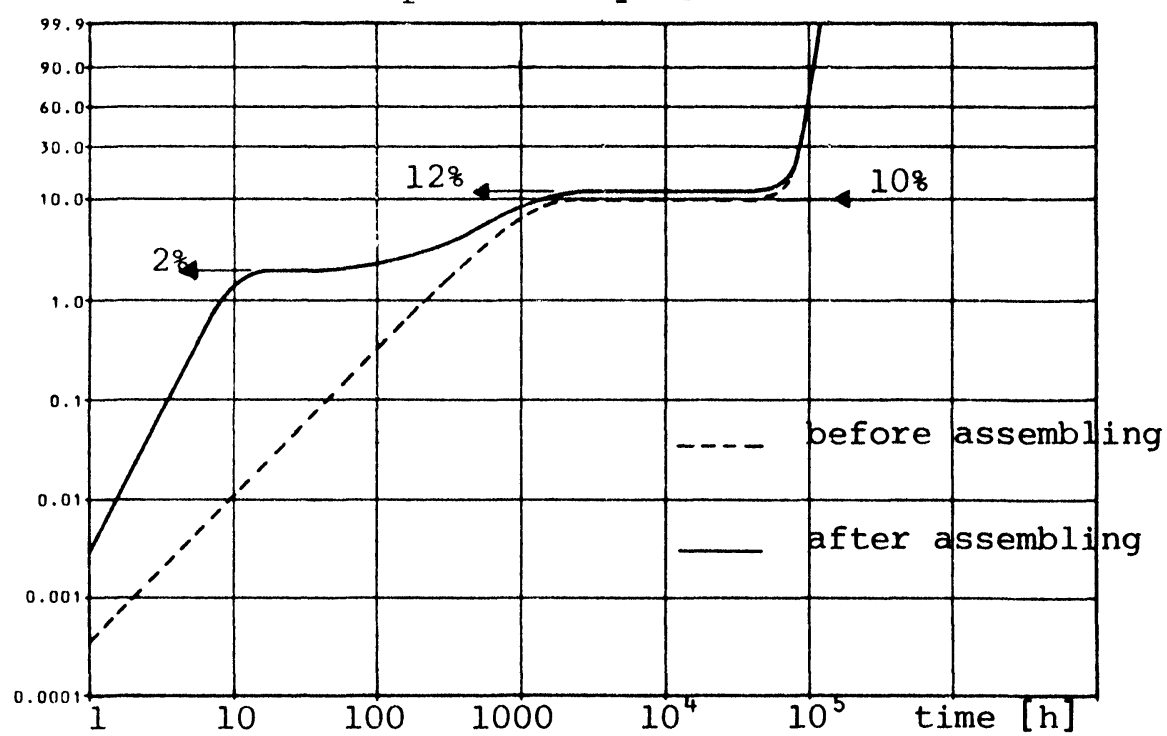

FIGURE 1 The failure patterns for a component type with a trimodal failure distribution (from ref. 1) 


\section{A DEFINITION OF RELIABILITY INDICATOR METHODS}

Before entering a detailed description of some (recently developed) reliability indicator methods, it may be worthwhile to describe the concept a bit more precisely. A reliability indicator method is - as the name suggests - a testing method which yields results that are indicative for the reliability of a single component or a batch of components. Furthermore the testing time should be very short and, preferably, virtually zero for each component. Finally the method in general consists of the actual measurements as well as an analysis of the data.

It is important to notice that there are two types of reliability indicator methods: one indicating flaws in a specific component and another indicating the expected reliability of a component type. The former is a $100 \%$ screening test. The latter may be a sampling test aimed for an assessment of the reliability of a particular component batch.

Another important aspect is that the indication may be based on the measurement and analysis of a single parameter or a combination of parameters. The parameter or parameters may be normal functional parameters of the component but often they will be odd parameters with a more remote connection to the functional behaviour of the component.

The screening tests may be categorized as shown in Figure 2.

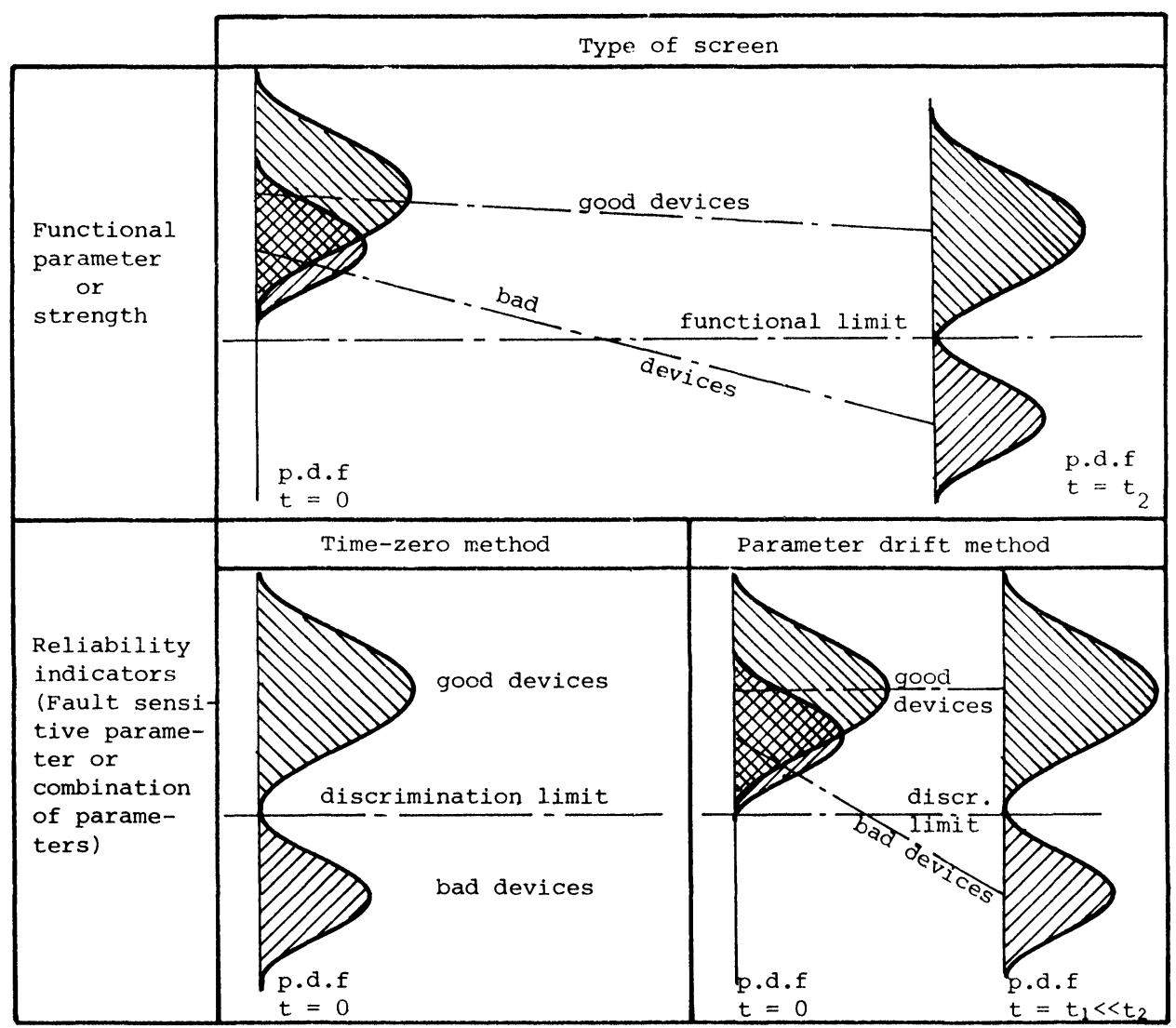

FIGURE 2 The principles of reliability indicator screening compared with the principal of functional failures (from ref. 7). 
While the functional parameter or strength degrades relatively slowly until at time $t=t_{2}$ when all the bad devices have failed, the reliability indicators discriminate the bad devices either at time zero or after a time $t_{1}$, considerably shorter than $t_{2}$.

Although not clearly stated, the reliability indicator methods do not include the well known accelerated tests. Where the latter are carried out until a sufficient number of components have failed, the indicator methods should be non-destructive.

\section{A REVIEW OF SOME RECENTLY PUBLISHED RELIABILITY INDICATOR METHODS}

The classical example of a reliability indicator method is the resistor non-linearity method which, since its birth in the sixties, has become a standard method for assessing the quality and reliability of resistors. This development has been greatly supported by the availability of measurement equipment especially made for this purpose. In the following text other indicator methods which have been published recently will be described. The methods under consideration are not intended to be a complete list, but merely some selected examples, showing the potential of the use of reliability indicator methods.

\section{3a C.M. Ryerson: "Reliability Testing and Screening: A General Review Paper"3}

Going through the different well known testing and screening methods, Ryerson concludes that these in most cases are inadequate to cope with the inherent unreliability caused by material or material-processing defects. He suggests putting emphasis on the drift in what he calls "indicator parameters", using a technique known as "Degradation Analysis". Unfortunately he neither describes this technique nor gives any references, but he defines the concept of indicator parameters as follows

"The reliability screening criteria are based on the inherent stability of "tell-tale" part parameters and the degradation to these parameters caused by operating stress with time. The degradation of these critical indicator parameters does not have to drift the parameters out of specification during the screening to justify rejection for reliability screening purposes"

and later

"Electrical parameters are of two types: Those related to definition of function and those indicative of incipient degeneration or failure. Sometimes the critical indicator parameters are also key functional parameters such as resistance or capacity. At other times they are secondary parameters as far as function is concerned such as dissipation factor or leakage. Some of the key parameters highly sensitive indicators of internal change or variation which can indicate potential or incipient unreliability. They must be defined for each instance of unique parts or unique application."

The quotations explain themselves and correspond with the concepts explained in Figure 2. Furthermore Ryerson gives a list of typical indicator parameters (see Table I).

\section{$3 b$ D.J. Ager et al.: "The Marginal Voltage Method" ",5,6}

The marginal voltage method constitutes a very good example of a reliability indicator method where a parameter is used at time-zero to indicate flaws in the components. The 
TABLE I

Typical reliability indicator parameters (from ref. 3)

\begin{tabular}{|c|c|c|}
\hline Part type & & Indicator parameters \\
\hline $\begin{array}{l}\text { Tantalum } \\
\text { capacitors }\end{array}$ & $\begin{array}{l}1 . \\
2 . \\
3 . \\
4 .\end{array}$ & $\begin{array}{l}\text { Leakage Current at } 25^{\circ} \mathrm{C} \\
\text { Capacitance at } 25^{\circ} \mathrm{C} \\
\text { Dissipation factor at } 25^{\circ} \mathrm{C} \\
\text { Leakage Current at } 65^{\circ} \mathrm{C}\end{array}$ \\
\hline $\begin{array}{l}\text { Paper Mular } \\
\text { capacitors }\end{array}$ & $\begin{array}{l}1 . \\
2 . \\
3 . \\
4 .\end{array}$ & $\begin{array}{l}\text { Insulation Resistance at } 25^{\circ} \mathrm{C} \\
\text { Capacitance at } 25^{\circ} \mathrm{C} \\
\text { Dissipation Factor at } 25^{\circ} \mathrm{C} \\
\text { Insulation Resistance at } 85^{\circ} \mathrm{C}\end{array}$ \\
\hline $\begin{array}{l}\text { Glass } \\
\quad \text { capacitors }\end{array}$ & $\begin{array}{l}1 . \\
2 . \\
3 .\end{array}$ & $\begin{array}{l}\text { Capacitance at } 25^{\circ} \mathrm{C} \\
\text { Dissipation Factor at } 25^{\circ} \mathrm{C} \\
\text { Insulation Resistance at } 25^{\circ} \mathrm{C}\end{array}$ \\
\hline $\begin{array}{l}\text { Ceramic } \\
\text { capacitors }\end{array}$ & $\begin{array}{l}1 . \\
2 . \\
3 . \\
4 .\end{array}$ & $\begin{array}{l}\text { Insulation Resistance at } 25^{\circ} \mathrm{C} \\
\text { Capacitance at } 25^{\circ} \mathrm{C} \\
\text { Power Factor at } 25^{\circ} \mathrm{C} \\
\text { Insulation Resistance at } 85^{\circ} \mathrm{C}\end{array}$ \\
\hline $\begin{array}{l}\text { Mica button } \\
\text { capacitors }\end{array}$ & $\begin{array}{l}1 . \\
2 . \\
3 . \\
4 .\end{array}$ & $\begin{array}{l}\text { Insulation Resistance at } 25^{\circ} \mathrm{C} \\
\text { Capacitance at } 25^{\circ} \mathrm{C} \\
\text { "Q" at } 25^{\circ} \mathrm{C} \\
\text { Insulation Resistance at } 85^{\circ} \mathrm{C}\end{array}$ \\
\hline Film resistors & $\begin{array}{l}1 . \\
2 .\end{array}$ & $\begin{array}{l}\text { Resistance at } 25^{\circ} \mathrm{C} \\
\text { Noise at } 25^{\circ} \mathrm{C}\end{array}$ \\
\hline Diodes & $\begin{array}{l}1 . \\
2 . \\
3 . \\
4 . \\
5 .\end{array}$ & $\begin{array}{l}\mathrm{I}_{\mathrm{R}} \text { Reverse Leakage } \\
\mathrm{V}_{\mathbf{i}} \text { Forward Voltage Drop } \\
\text { TCBV Thermal Coefficient } \\
\mathrm{V}_{\mathrm{z}} \text { Zener Voltage } \\
\mathrm{Z}_{\mathrm{z}} \text { Zener Impedance }\end{array}$ \\
\hline Transistors & $\begin{array}{l}1 . \\
2 . \\
3 . \\
4 . \\
5 . \\
6 . \\
7 . \\
8 . \\
9 .\end{array}$ & $\begin{array}{l}\mathrm{h}_{\mathrm{FE}} \text { Beta } \\
\mathrm{I}_{\mathrm{CBO}} \text { Leakage Current (collector to base) } \\
\mathrm{P}_{\mathrm{g} \text { Power Gain }} \\
\mathrm{V}_{\mathrm{CE}} \text { (Sat) Saturation Voltage } \\
\mathrm{h}_{\mathrm{FE}} / \mathrm{h}_{\mathrm{FE}} \text { Beta Ratio } \\
\mathrm{I}_{\mathrm{PSS}} \text { Leakage Current (drain to source) } \\
\mathrm{I}_{\mathrm{GSS} \text { Leakage Current (gate to source) }} \\
\mathrm{BV}_{\mathrm{CEO} \text { Breakdown Voltage (collector to emitter) }} \\
\mathrm{V}_{\mathrm{p}} \text { Gate to Pinch-off Voltage at Reverse-Biased Drain }\end{array}$ \\
\hline
\end{tabular}

method is non-destructive and has been proved useful for TTL circuits. It should, according to the authors, be useful for CMOS circuits as well. However, they have not published any results for these.

The basic principle is to decrease the supply voltage until the digital circuit under test gives an output failure when subjected to a correct input signal. The supply voltage at which the failure occurs is called the marginal voltage for the circuit. Each input/output combination has its own marginal voltage and the more complex a circuit is, the more measurements have to be made. For example a TTL type 7482 2-bit adder has 32 marginal voltages, while a TTL type 7485 4-bit magnitude comparator has 2048 marginal voltages.

It is shown that a circuit without defects has fairly constant marginal voltages. However, a circuit with defect shows some marginal voltages considerably higher than the normal values, (see Figure 3). Furthermore, by measuring the change in the high marginal voltages while the circuit surface is scanned by a light spot, it is possible to locate the defect. 


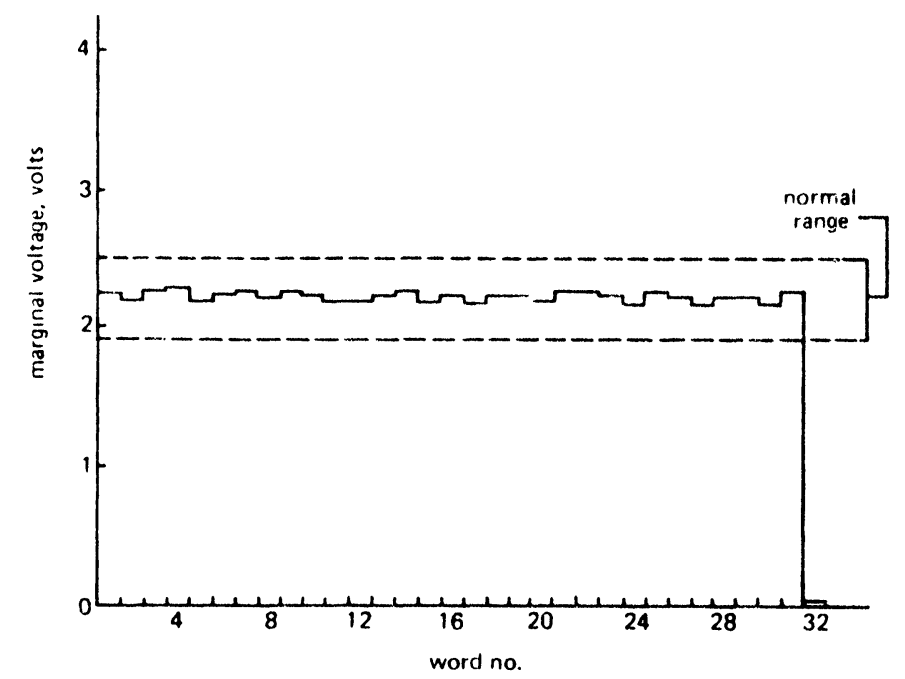

FIGURE 3a Typical marginal voltage results for a TTL type 7482 2-bit adder (from ref. 4)

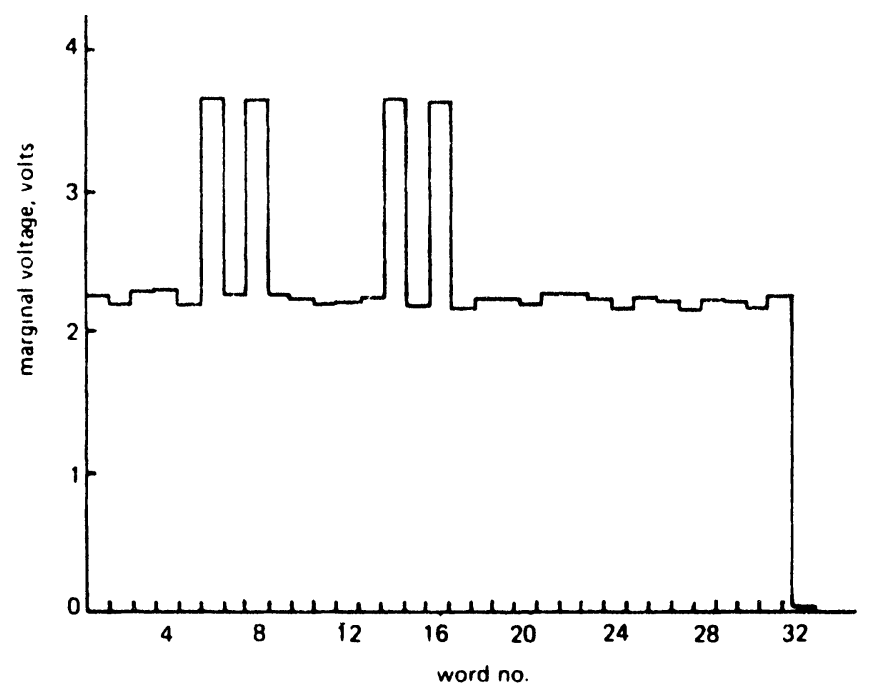

FIGURE 3b Example of anomalous marginal voltage plot for a TTL type 7482 2-bit adder (from ref. 4).

The marginal voltage may be measured in three ways. The authors call them

- the permanent marginal voltage,

- the dynamic marginal voltage and

- the immediate marginal voltage.

These three ways correspond to the functional properties of the circuits. Permanent marginal voltages describe the critical supply voltages which just allow the retention of uncorrupted data. Dynamic marginal voltages describe the critical supply voltages which govern their correct dynamic operation. Immediate marginal voltages reflect misoperation in combinational paths which are directly associated with the output terminals. 
The authors report to have found (even for relatively simple TTL circuits) that approximately $10 \%$, on average, yield anomalous marginal voltage results attributable to internal defects and suggest that these defects may well contribute to the intermittent operation faults, which sometimes degrade the performance of complex electronic systems. If this suggestion is correct, the marginal voltage method is a very powerful tool for preventing the troublesome intermittent faults.

The marginal voltage method looks very promising, because an anomalous marginal voltage is proved to be the result of an internal defect. In a particular application this defect may not be hazardous, but nevertheless it may be safer to screen the component out.

\section{3c T. Takahashi et al.: "The Non-Radiative Recombination Current Method""}

Light emitting diodes (LED's] suffer from degradation of the emission efficiency. This degradation can be attributed to an increase in the non-radiative recombination current. The measurement of the drift in this current over a short time span may reveal the bad devices. The authors report the two cases shown in Figure 4.

However, as seen from the figure, the screening takes considerably longer for good quality devices (case 2), than for bad quality devices (case 1).

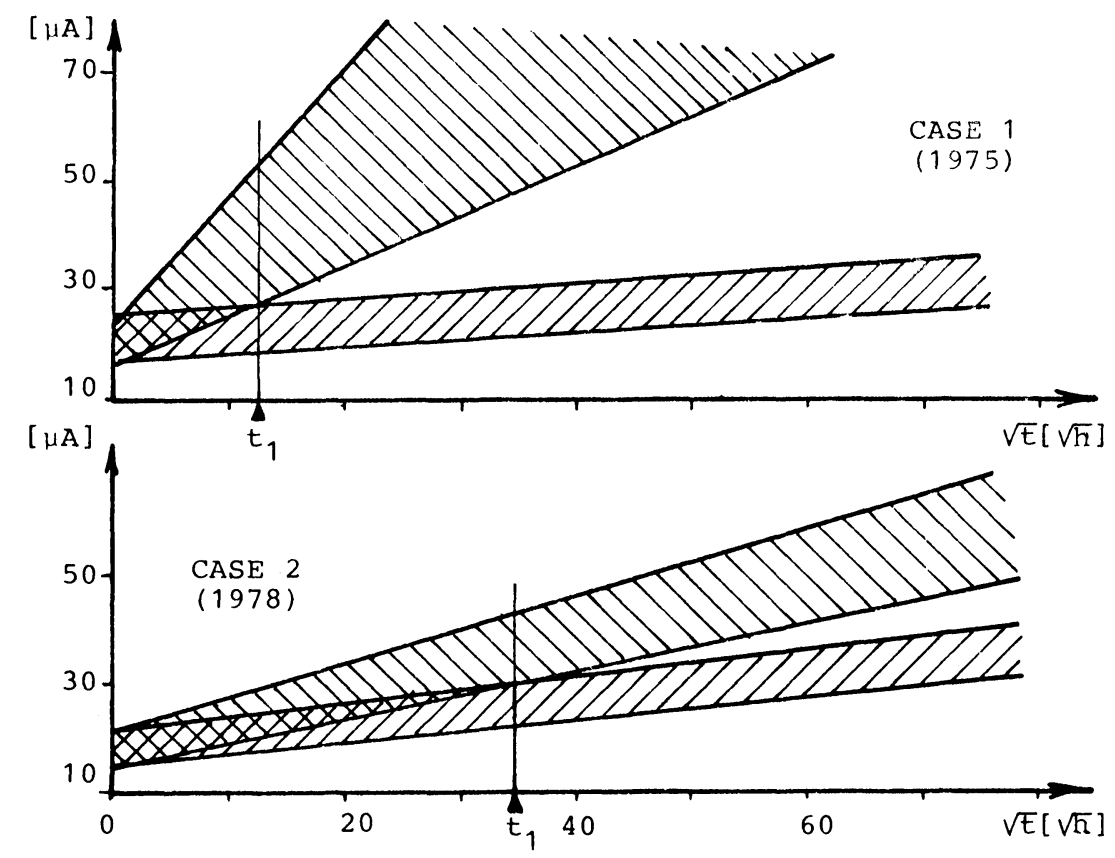

FIGURE 4 The non-radiative recombination current of GaAs-diodes versus $\sqrt{ }$ time. (The junction temperature is $80^{\circ} \mathrm{C}$ and the current density is $350 \mathrm{~A} / \mathrm{cm}^{2}$ in both cases (from ref. 7).

\section{3d T. Takahashi et al.: "The Reverse Recovery Time Method"7}

Another method for screening LED's is the reverse recovery time method. This method is essentially a time-zero method. The method is based on an analysis of the physics of the failure mechanisms and the authors have proved its applicability by a correlation study 
between initial measurements of the reverse recovery time and the degradation in emission efficiency during a life test. Figure 5 shows the measurement method and the results for a (red) GaAs LED.
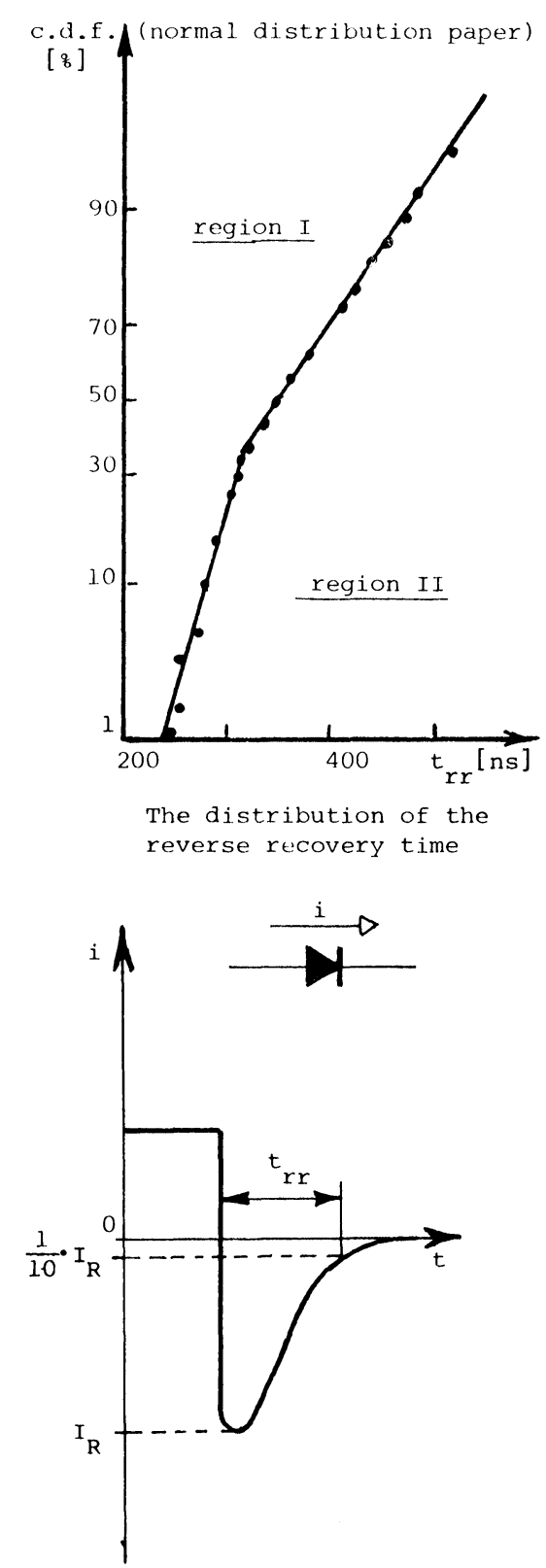

The definition of the reverse recovery time $t_{r r}$

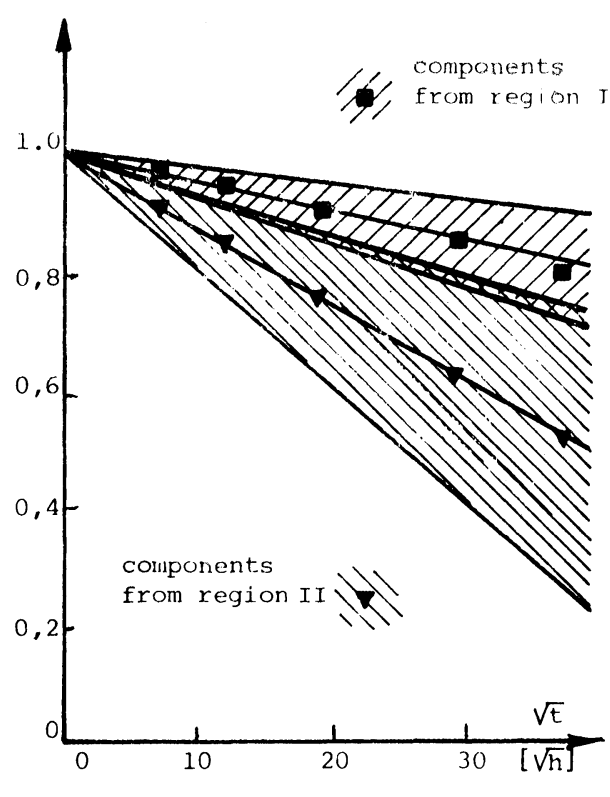

Time dependendancy of the relative emission efficiency

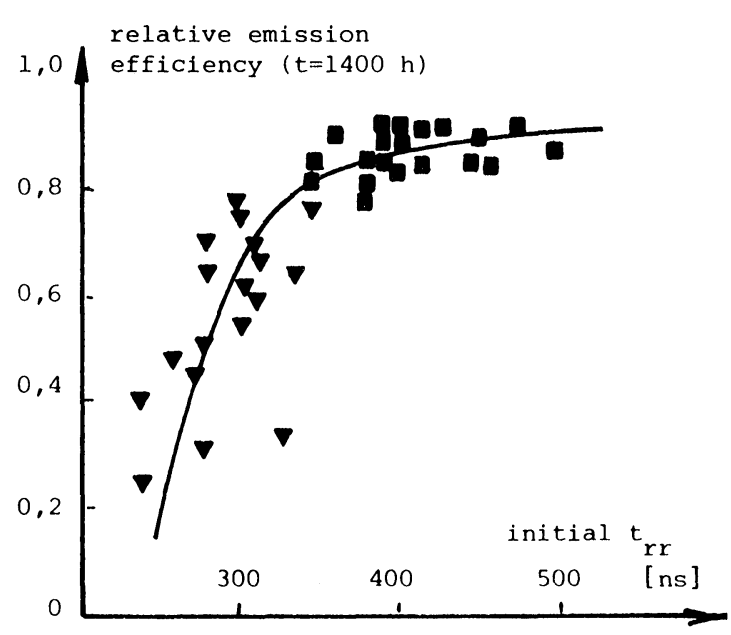

Scatter diagram of the relative emission efficiency at 1400 hours versus the initial value of the reverse recovery time

FIGURE 5 The reverse recovery time method applied on GaAs LED's (from ref. 7). 


\section{3e Robert H. Gusciora: "The Contact resistance Standard Deviation Method"8}

Film contamination on contact surfaces are well known failure causes during operational life. The dry circuit contact resistance is known as an indicator of contamination. In the present case the author concentrates on the variation in a sample of contacts from a production line. He shows that a standard deviation less than $10 \%$ of the mean value is indicative of an insignificant amount of processing residues on the contacts. This "rule-of-thumb" is useful as a batch acceptance procedure. Furthermore it is not necessary to measure with extreme low voltages ( $20 \mathrm{mV}$ or less). Although a voltage of $100 \mathrm{mV}$ to a certain extent destroys the film, the variability still shows up and the "10\% rule-of-thumb" will be applicable.

\section{3f R.S. Sayles: "The Discriminant Function Method"9}

This method combines several parameters into a reliability index for each of the tested components. The sign or the magnitude of the index indicates whether the component is prone to fail early (due to flaws) or is a good device.

The first step in the method is to identify the parameters to be measured and the associated discriminant function (DF). Calling the measured parameters $x_{1}, x_{2}, x_{3}-x_{n}$, the DF has the form

$$
S=a_{1} x_{1}+a_{2} x_{2}+-+a_{n} x_{n}
$$

where $a_{1}, a_{2}-a_{n}$ are weighting factors. The weighting factors are optimized to give maximum discrimination between the component groups, here the bad components (group A) and the good components (group B). The optimization is done from the knowledge of the mean difference between the groups, the variances within groups and the covariances between measurements within groups. So it is necessary to have some prior knowledge about the groups.

After establishing the DF a reference index is calculated for each group by inserting the (expected) mean values for each parameter into the function. In the present case we get:

Reference index for group A (bad components)

$$
S_{\mathrm{AM}}=\mathrm{a}_{1} \overline{\mathrm{x}}_{1 \mathrm{~A}}+\mathrm{a}_{2} \overline{\mathrm{x}}_{2 \mathrm{~A}}+-+\mathrm{a}_{\mathrm{n}} \overline{\mathrm{x}}_{\mathrm{nA}}
$$

Reference index for group B (good components)

$$
\mathrm{S}_{\mathrm{BM}}=\mathrm{a}_{1} \overline{\mathrm{x}}_{1 \mathrm{~B}}+\mathrm{a}_{2} \overline{\mathrm{x}}_{2 \mathrm{~B}}+-+\mathrm{a}_{\mathrm{n}} \overline{\mathrm{x}}_{\mathrm{nB}}
$$

where $\bar{x}_{1 A}-\bar{x}_{n A}$ and $\bar{x}_{1 \mathrm{~B}}-\bar{x}_{n B}$ are the means of parameters for respectively group $A$ and group B components.

Now measurements on the components in a new (unknown) batch are made. For each set of measurements the reliability index $S=a_{1} x_{1}+-+a_{n} x_{n}$ is calculated, and if it is closest to $S_{A M}$ the component is deemed bad. If $S$ is closest to $S_{B M}$ the component is regarded as a good device.

The author reports how the method is applicable to mechanical seals. One of the cases considers a lip seal which is screened by the use of 3 to 9 parameters. It is important to notice that the parameters are selected on the basis of the failure mechanisms involved. After the screening into two groups, all components - bad as well as good - are subjected to a life test. The results of the lifetests are correlated with the screening results as shown in Figure 6. From this figure it is seen that the DF screen is very efficient with 9 para- 


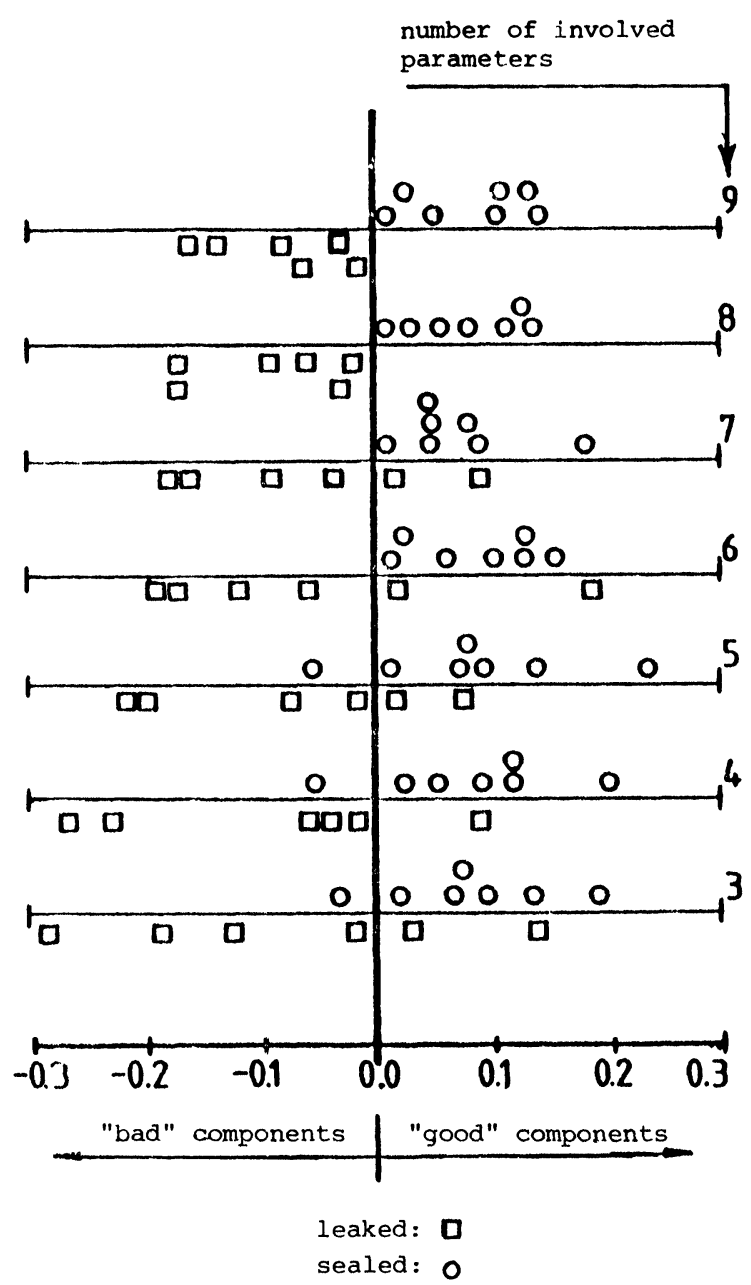

FIGURE 6 Correlation between DF-screening and results from life tests on lip seals.

meters involved. It is, however, possible to go down to four or maybe even three parameters and still retain a fair screening efficiency.

\section{$3 g$ Arnold Berman: "The Dielectric Breakdown Ramp Method"10}

The time-to-failure distribution function for dielectric breakdown failures can be forecast on the basis of a distribution function for the "accumulated" electric field required to create a breakdown.

The "accumulated" electric field distribution function is measured by applying a voltage ramp function to a sample of the dielectric under consideration and by determining the electric field magnitudes at which breakdowns occur. The p.d.f. of the breakdown field $\mathrm{E}_{\mathbf{B}}$ is called the ramp histogram.

Let us consider the hypothetical ramp histogram in Figure 7. If $\mathrm{E}_{\mathrm{A}}$ is the applied field under use conditions the area below $\mathrm{E}_{\mathrm{A}}$ will be the time-zero proportion of defective dielectrics. 


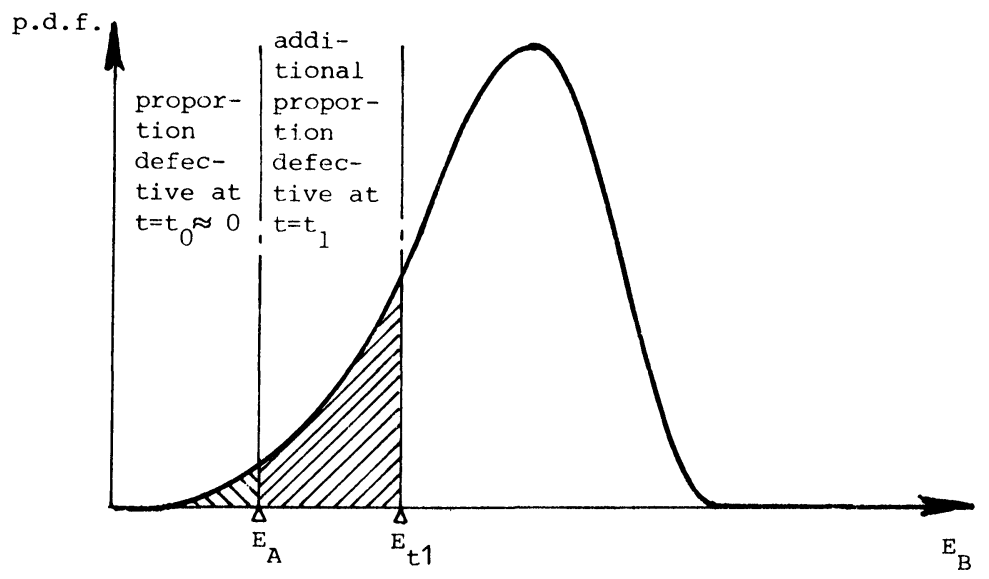

FIGURE 7 The ramp histogram (from ref. 10).

If we want to predict the additional failure proportion at a time $t_{1}$ we calculate a corresponding field $E_{t 1}$ from

$\mathrm{E}_{\mathrm{t} 1}=\mathrm{E}_{\mathrm{A}}+\frac{1}{\gamma} \ln \frac{\mathrm{t}_{1}}{\mathrm{t}_{0}}$

where $\gamma$ is material constant and $t_{0}$ is derived from the measuring ramp slope $\alpha$ by

$\mathrm{t}_{0}=\frac{1}{\gamma \alpha}$

The accumulated proportion failures at $t=t_{1}$ are found as the area between $E_{A}$ and $E_{t 1}$. If this calculation is done for every value of $t$ within the useful life, the time-to-failure distribution function for the time dependent dielectric breakdown failures will emerge.

The idea is applicable for the design of screening purposes as well. If the ramp histogram has a tail or a "hump" in the lower end, this can be screened out by applying a brief constant field $E_{S}$ for a time $t_{S}$. The tail will then be truncated as illustrated in Figure 8. The

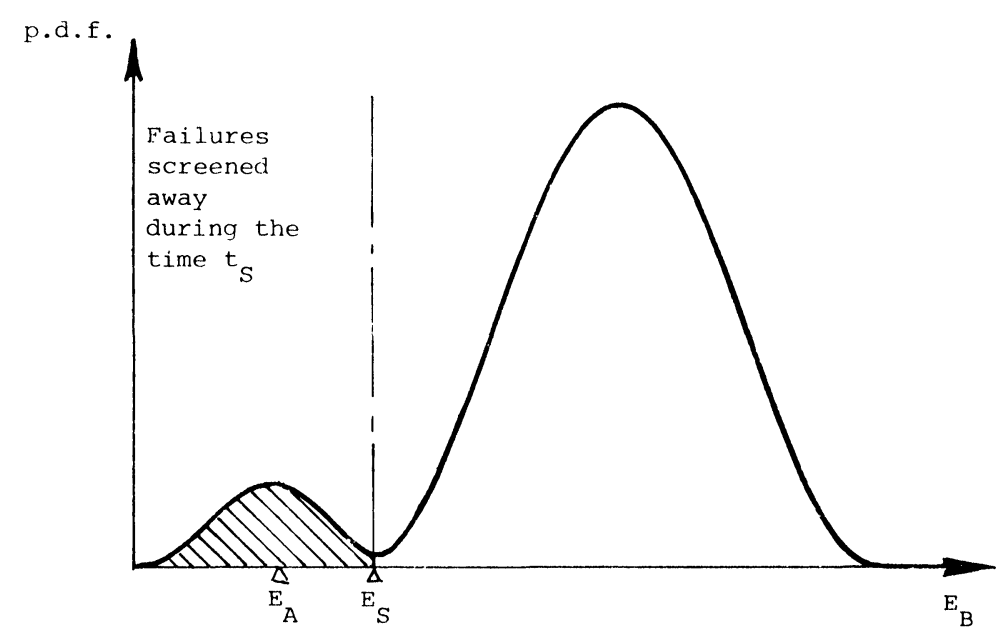

FIGURE 8 The design of screening from the ramp histogram. 
screening field necessary to ensure a failure-free operation up to a time is given by

$\mathrm{E}_{\mathrm{S}}=\mathrm{E}_{\mathrm{A}}+\frac{1}{\gamma} \ln \frac{\mathrm{t}}{\mathrm{t}_{\mathrm{S}}}$

It should finally be mentioned that the temperature dependency of the dielectric breakdown is taken into account through $\gamma$ which for $\mathrm{SiO}_{2}$ follows the function

$\gamma=0,4 \mathrm{e}^{\frac{0.07}{\mathrm{kT}}}$ [decades pr. MV/cm]

in which the product $\mathrm{kT}$ of Boltzmann's constant and the absolute temperature is inserted in $\mathrm{eV}$.

\section{3h T. Ajiki et al. and R.L. Wiker et al.: "The Threshold Voltage Drift Method"11,12}

So far we have been considering time-zero methods. However, as pointed out in part 2 parameter drift methods offer another possibility. An example is the reliability assessment of MNOS memories by the drift in the threshold voltages.

The method is based on the knowledge that the threshold voltage versus time is a lin-log function. This makes it possible to estimate the retention time by extrapolation from a short time measurement, see Figure 9.

The method may be used for screening purposes as well. In reference 12 this is described in detail. By the use of nomograph technique a screening criterion for a 160 hour burn-in is derived. The threshold voltage $V_{T 1}$ after 3 hours, the threshold voltage $V_{T 2}$ and the reference voltage after 160 hours are measured at room temperature. From the nomograph

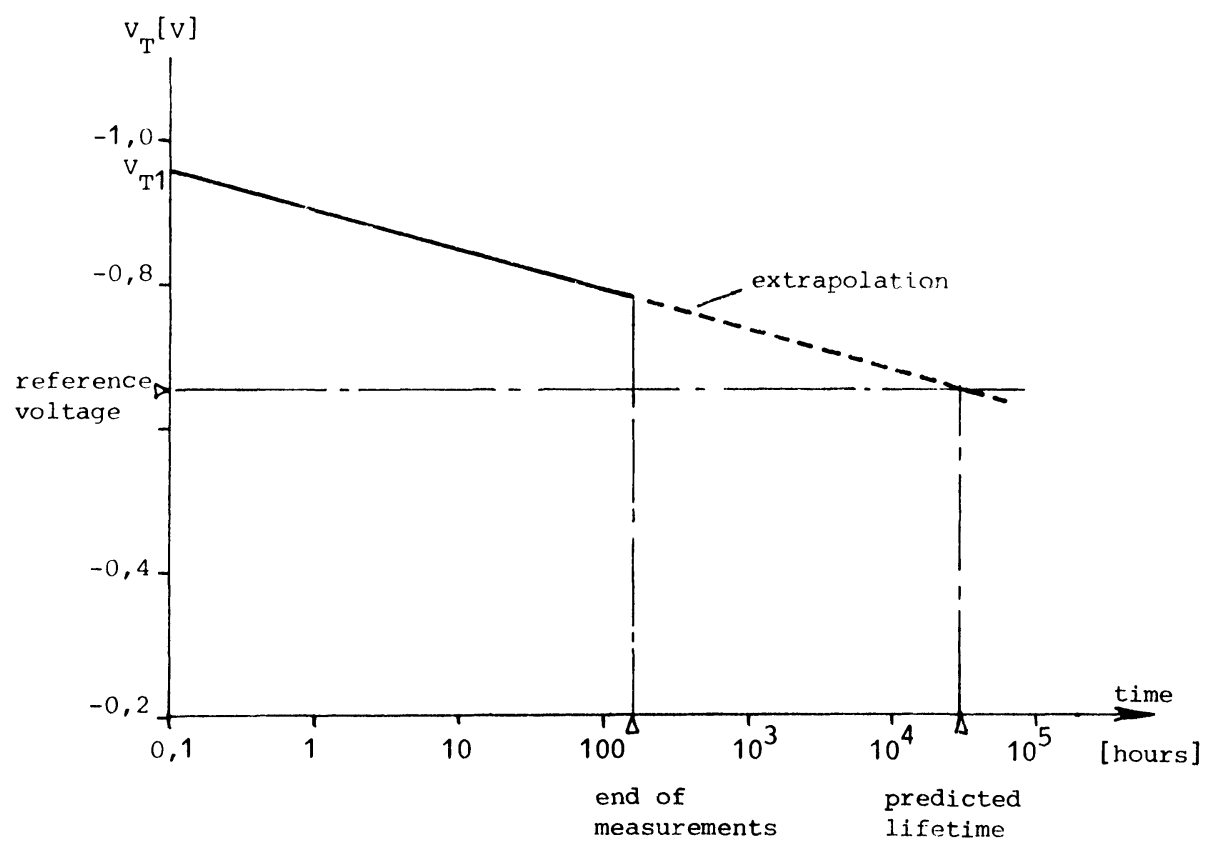

FIGURE 9 The principle of prediction the memory retention time from short time measurements (from ref. 11). 
in Figure 10 the minimum which $\mathrm{VT}_{2}$ may be for the device to have a retention of one year is depicted. If the actual measured $\mathrm{VT}_{2}$ is above this value the memory is accepted. If it is below the memory is rejected.

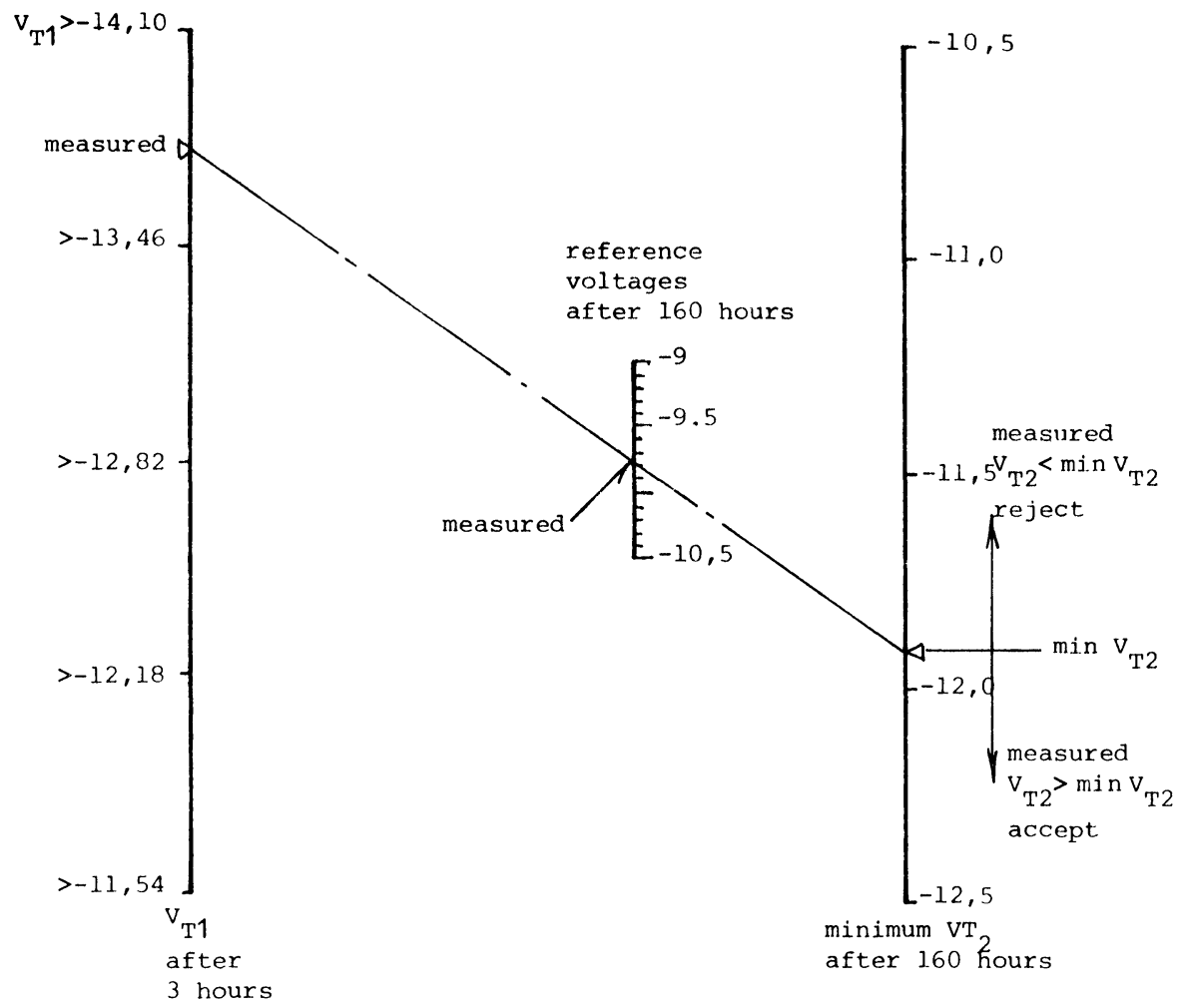

FIGURE 10 Retention nomograph for ER3400/NCR2451 Devices (from ref. 12).

3i G. Bosch and J. Mфltoft: "Algorithms for the Estimation of Reliability from parameter measurements ${ }^{\prime \prime 13,14}$

For the assistance of parameter screening methods two algorithms which have been published recently, shall be mentioned.

B. Bosch ${ }^{13}$ assumes a correlation between the initial value of a parameter and its pattern of drift. This assumption enables one to predict the time-to-failure distribution from the initial distribution of the parameter under consideration.

$\mathbf{J}$. M $\phi$ ltoft $^{14}$ assumes statistical independence between the initial value of the parameter and its subsequent drift pattern. From the knowledge of the initial distribution, the parameter drift equation and the distribution of the drift it is possible to calculate the time-tofailure distribution.

Neither of the methods are universal as the assumptions are not applicable in general. They are merely supplementary to each other and may be applied after an assessment of the degradation mechanism involved.

$3 j$ Walter H. Schroen et al., James L. Spencer et al. and R.J. Usell et al.: "The Integrated Monitor Method"15,16,17

Reliability indicator methods are not restricted to those based solely on measurements of parameters of the components themselves. Reliability sensitive devices could be built into 
the components. An example is the use of built-in strain gauges, whose purpose is to indicate the mechanical stress induced in the chip by the encapsulation process. The strain gauge may be an integral part of the monolithic circuit as reported in references 15 and 16 .

As suggested in reference 15 the idea could be expanded to include monitors for moisture, insulator integrity, leakage current etc.

\section{CONCLUSION}

The necessity for some methods of early indication of and screening out of possible flaws in electronic components is described. Reliability indicator methods offer a possible solution. This is supported by examples published within the last couple of years. The examples cover a range from time-zero methods to parameter drift methods, from reliability assessment methods to screening methods and from the wafer level to the finished components. As components become more and more complex and as the pace of technological development increases, reliability indication methods are likely to become one of the major diagnostic tools for the component manufacturer as well as for the component user.

\section{REFERENCES}

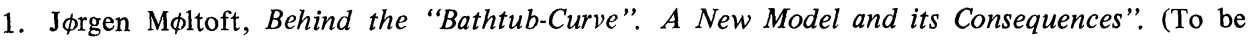
published)

2. Finn Jensen, N.E. Petersen, Burn-in, An Engineering Approach to the Design and Analysis of Burn-in Procedures. (John Wiley and Sons, 1982).

3. C.M. Ryerson, "Reliability Testing and Screening: A general Review Paper". Microelectronics Reliability, 17, (1978).

4. D.J. Ager, J.C. Henderson, "The Use of Marginal Voltage Measurements to Detect and Locate Defects in Digital Microcircuits" 19th Annual Proceedings, Reliability Physics, Symposium, Orlando, U.S.A. (1981).

5. D.J. Ager, G.F. Cornwell, I.W. Stanley, "The Application of Marginal Voltage Measurements to Detect and Locate Defects in Digital Microcircuits" Microelectronics and Reliability, 22, (1982).

6. D.J. Ager, G.F. Cornwell, C.E. Stephens, "A Light Sensitive Marginal Voltage Technique for the Location of Defects in Digital Microcircuits" Proceedings Third National Reliability Conference, Birmingham, U.K. (1981).

7. T. Takahashi, S. Todoroki, S. Mitani, “A New Screening Method for Optocouplers and LED's" 17 th Annual Proceedings, Reliability Physics Symposium, U.S.A. (1979).

8. Robert H. Gusciora, "Predict Contact Performance with Film Measurements" Proceedings, 27th Electronic Components Conference, U.S.A. (1977).

9. R.S. Sayles, "The Use of Discriminant Function Techniques in Reliability Assessment and Data Classification" 6th Advances in Reliability Technology Symposium, Bradford, U.K. (1980).

10. Arnold Berman, "Time-Zero Dielectric Reliability Test by a Ramp Method" 19th Annual Proceedings, Reliability Physics Symposium, Orlando, U.S.A. (1981).

11. T. Ajiki, M. Sugimoto, H. Higudi, S. Kumada, "Temperature Accelerated Estimation of MNOS Memory Reliability" 19th Annual Proceedings, Reliability Physics Symposium, Orlando, U.S.A. (1981).

12. R.L. Wiker, R. Carter, "Accelerated Testing of Time Related Parameters in MNOS Memories" 19th Annual Proceedings, Reliability Physics Symposium, Orlando, U.S.A. (1981).

13. G. Bosch, "Model for Failure Rate Curves" Microelectronics and Reliability, 19, (1979).

14. J. Mфltoft, "The Failure Rate Function Estimated From Parameter Drift Measurements" Microelectronics and Reliability, 20, (1980).

15. Walter H. Schroen, James L. Spencer, John A. Bryan, Robert D. Cleveland, Terry D. Metzgar and Darvin R. Edwards, "Reliability Tests and Stress in Plastic Integrated Circuits" 19th Annual Proceedings, Reliability Physics Symposium, Orlando, U.S.A. (1981).

16. James L. Spencer, Walter H. Schroen, George A. Bednarz, John A. Bryan, Terry D. Metzgar, Robert D. Cleveland and Darvin R. Edwards, "New Quantitative Measurements of IC Stress Introduced by Plastic Packages" 19th Annual Proceedings, Reliability Physics Symposium, Orlando, U.S.A. (1981).

17. R.J. Usell (Jr) and S.A. Smiley, "Experimental and Mathematical Determination of Mechanical Strains within Plastic IC Packages and their Effect on Devices During Environmental Tests." 19th Annual Proceedings, Reliability Physics Symposium, Orlando, U.S.A. (1981). 

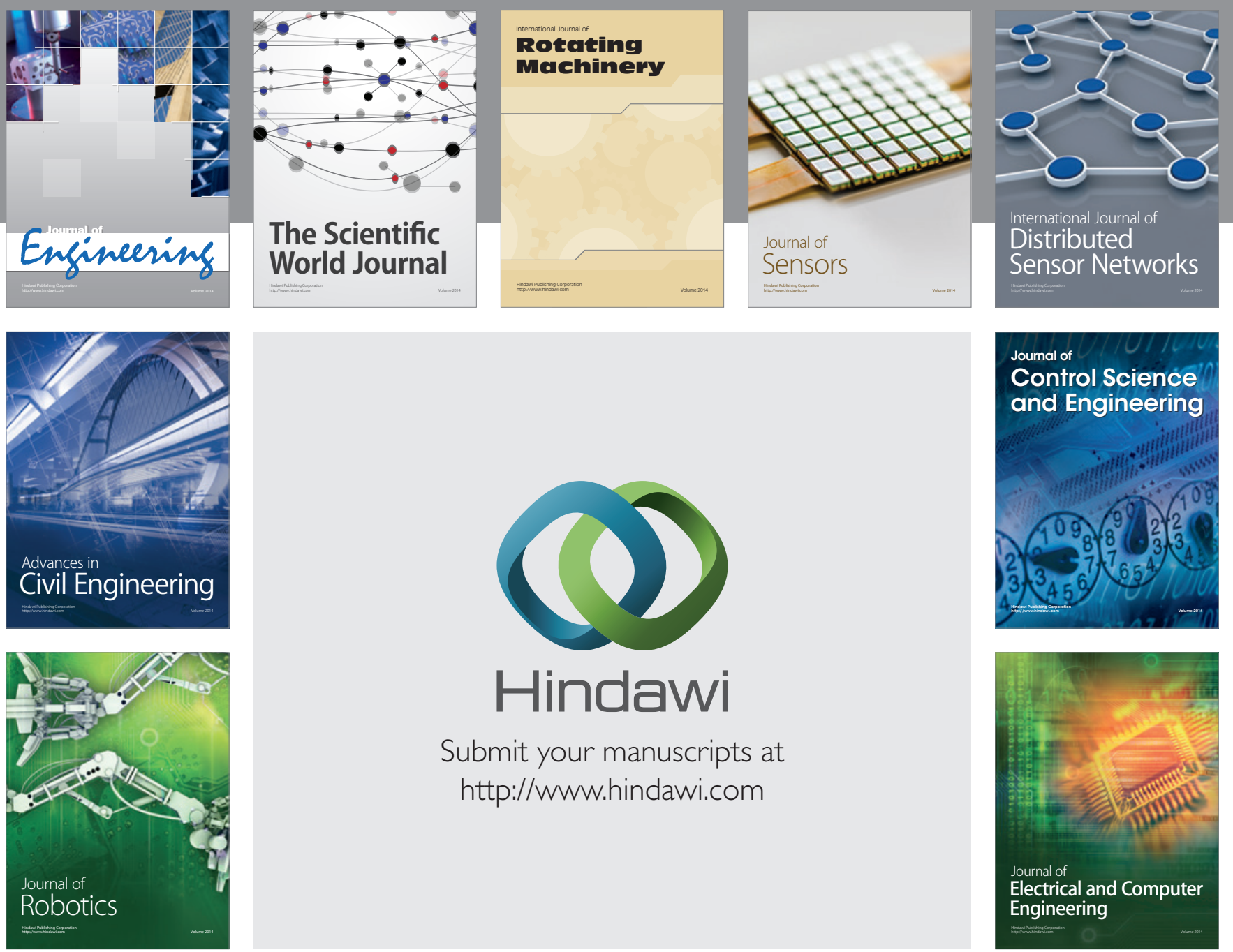

Submit your manuscripts at

http://www.hindawi.com
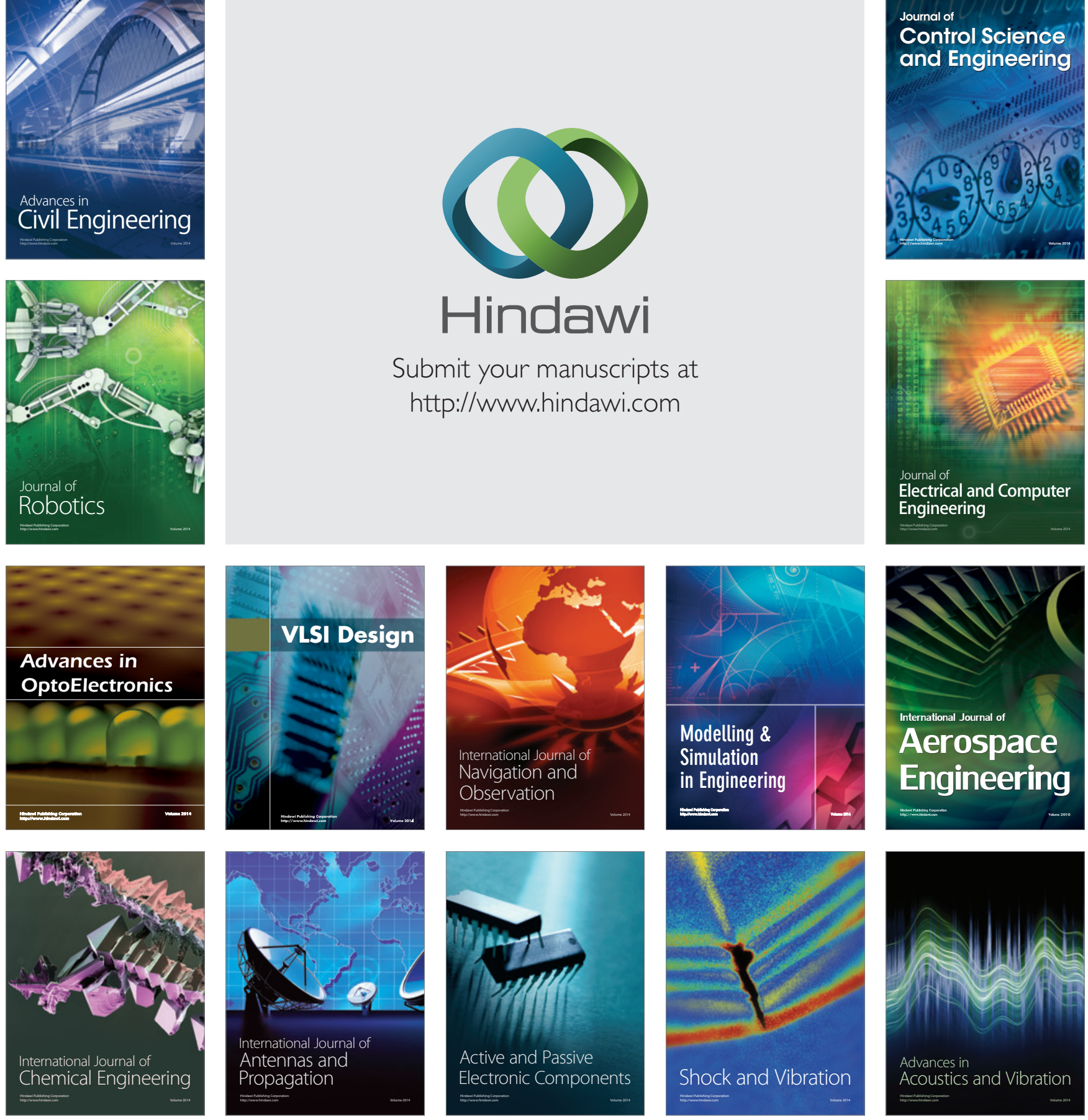